\title{
"Individual" Social Capital, "Social" Networks, and Their Linkages to Economic Game
}

MASAHIKO AOKI

This essay makes a conceptual distinction between societal categories, such as social networks, norms, and social status differentiation, on the one hand, and social capital invested by individual agents on the other. The former are institutional phenomena arising as outcomes of social-exchange games in which individual agents invest strategically in social capital. Recent development of neuroscience suggests the future possibility of measuring social payoffs in terms of trade-off relationships with hedonic payoffs. This possibility may suggest that a linked-game approach to social capital and its implications for economic performance are more promising. This approach might make feasible an analysis of socioeconomic networks that is not possible using an economic or sociological approach in isolation. Particularly, this essay suggests a way to apply the linked-game approach to the problem of the tragedy of the commons, which is becoming one of the most acute public issues of our time.

About 10 years ago, Partha Dasgupta and Ismail Serageldin edited a useful volume on social capital based on a years-long project of the World Bank (Dasgupta and Serageldin 1999). Articles included in that volume exhibited varied views on the concept and ways it can be used in economic analysis, and, in spite of the lucidly executed concluding chapter by Dasgupta that impartially summarized the contents and presented his own comprehensive view, the divide on the concept was not reconciled. Particularly troublesome was the fact that the two giants among contemporary economistsKenneth Arrow and Robert Solow-raised clear objections to the concept of social capital. Arrow (1999) urged "the abandonment of the metaphor of capital and the

\footnotetext{
Masahiko Aoki is the Henri and Tomoye Takahashi Professor Emeritus of Japanese Studies in the Economics Department and senior fellow of the Stanford Institute of Economic Policy Research and the Freeman Spogli Institute for International Studies at Stanford University. He is also director of the Virtual Center for Advanced Studies in Institutions (VCASI) at the Tokyo Foundation. 
term 'social capital." Solow (1999) concurred in being "critical of the concept of social capital and the way it is used." What were the reasons for their objections? Arrow, while admitting the plausibility of the hypothesis that social networks could affect economic performance, pointed out that "the reward for social interactions is intrinsic" and lacks the important property of capital as saved for future benefit at deliberate sacrifice today. Solow argued that various things normally referred to as social capital, such as "trust, the willingness to cooperate and coordinate, [and] the habit of contributing to a common effort even if no one is watching," may be referred to as "behavior patterns" and that the concept of capital in the usual sense of which stock and return can be measured may not be appropriate. Another point made was that social networks or behavior patterns may have positive or negative impacts on economic performance and therefore cannot be considered factors of production like physical or human capital.

In this paper, I dare to stand like a dwarf on the shoulders of the giants and try to see the landscape more clearly. That is, I would like to face squarely these problems and explore whether social capital can still be a useful concept in understanding economic performance. I sense first of all that one of the sources of the divide or debate is that proponents of the concept did not make a clear distinction between-or did not clarify the possible relations between-collective phenomena (or institutional phenomena), such as "social networks" or social "behavior patterns," on the one hand, and individual actions leading to the accumulation of the so-called social capital, on the other. This question may be related to the "micro-macro transformation problem," in Coleman's phrase (Coleman 1988, 1990). Or it may correspond to relations between equilibrium of some kind of social game and individual strategic choices that generate the outcome in the game-theoretic sense. Or, more concretely, one may ask, Who owns social capital: society or the individuals composing it? Second, what really makes social capital, if it exists, distinct from physical capital, human capital, public goods, and so on. What is the "social" about? If it is made definitely distinct from these economic entities, how is it related to economic performance?

In the last few decades, economists have been concerned with trust, norms, and the like, the essence of which is lucidly summarized by Dasgupta (1999). In such ventures, economists regard trust and norms endogenously generated through repeated economic transactions (for example, Kandori 1992; Greif 1994). They represent equilibrium patterns of economic behavior by rational agents. Sociologists, like Granovetter (1985), criticize economists for neglecting the fact that social networks embed and thereby constrain or facilitate (rational) economic transactions. Some economists are prompted to measure "social capital" and "trust" and estimate their impacts on economic performance (for example, La Porta and others 1997; Knack and Keefer 1997; Glaeser, Laibson, and Sacerdote 2002). Which way is right? Is social capital an endogenous variable or an exogenous parameter for economic analysis? Is there a third way of looking at relations between economic and social factors?

In this paper, I explore answers to these questions. I first conceptualize a special type of game-a social-exchange game-distinct from the economic-exchange game. In the social-exchange game, agents invest in their own "social capital" as 
individual strategies, while social networks or patterns of behavior with certain characteristics emerge as equilibrium among them. Then I link this game with games in the economic or commons domains and see how individual accumulation and use of social capital in the linked games may generate certain economic outcomes not viable if those economic games stand alone. Possible applications of this idea to economic development and social-economic networks in the informationcommunications industry and the commercialization of life science are mentioned briefly. Then I discuss how the attribution of differentiated social capital among the agents does, or does not, control the rat race in organizational context, quoting an example drawn from the recent financial crisis. Finally, I apply the notion of individually investible social capital to business corporations. I posit that corporate social capital, as distinct from physical and market-specific reputation capital, may be accumulated by individual business corporations through a corporate social responsibility program and examine its potentially significant implications for business strategy and public interests. A final section concludes.

\section{Conceptualizing an Individual's Social Capital: The Social-Exchange Game Approach}

One of the early proponents of the concept of social capital, James Coleman, employed the following interesting analogy to introduce the concept (Coleman 1988, 20):

If $\mathrm{A}$ does something for $\mathrm{B}$ and trusts $\mathrm{B}$ to reciprocate in the future, this establishes an expectation in A and an obligation on the part of B. This obligation can be conceived as a credit slip held by A for performance by B. If A holds a large number of these credit slips, for a number of persons with whom A has relations, then the analogy to financial capital is direct. These credit slips constitute a large body of credit that A can call in if necessary-unless, of course, the placement of trust has been unwise, and these are bad debts that will not be repaid.

Here a game-theoretic notion of social capital as individual assets, independent of their social-systemic consequences, is clearly elucidated. But what kinds of exchanges are involved (What does A do for B?), and what are the payoffs (What is the nature of returns to credit slips?) in those exchanges? How are they different from economic exchanges? Are A and B necessarily placed in symmetric positions to generate social networks characterized by mutual trust and so on?

As mentioned, economists have been endogenizing the notion of trust and social norms as a possible outcome of a reputation game in the economic domain itself. For example, if there is a credible belief among the agents in the community of traders that cheating a trading partner would surely result in the exclusion from further transactions in the community and if they are reasonably far-sighted, then they might refrain from cheating, and honest trading might be supported. But there can be situations where access to some economic goods cannot be denied for technological and other reasons: for example, use of the natural environment. Landscape cannot be hidden, water flow cannot be deflected, and air cannot be denied. But it is intuitive that there may be cases in which social norms could play a role even in such situations 
(for example, Ostrom 1990). The examination of this kind of situation has important implications for the problem of how to control one of the acute economic problems of today: global warming and other environmental problems. There are other cases of nonexcludability that may not be addressed, at least not entirely, with political commands, legal rules, and the like. To proceed, therefore, I consider first a kind of game that Coleman depicts purely as the social-exchange game and then recouple it with games of economic exchanges to examine implications of the linkage.

Suppose there is a community (group) of agents who mutually interact with each other by means of social symbols (such as words, gestures, gifts, and the like), physical actions (such as help or violence), or the offer of nonmarketable goods (such as valuable information, gossip, and the like) to affect the emotional payoffs of others. Let us call the set of such mutually interactive agents and the sets of their instruments as the domain of social exchanges and their recursive interactions as play of the social-exchange game. A few words may be due to distinguish this class of societal games from economic-exchange games.

First, although exchanges of social symbols (for example, speech acts) may be involved in other types of domains as well, those in the social-exchange domain are distinct because of the nature of the exchanges as well as the objectives of players. Any economic exchange is essentially a contract that cannot be implemented without a mutual agreement reached ex ante between two (or more) specific parties, although it may be unilaterally or bilaterally defaulted. However, social exchanges can be made without an explicit agreement, but with "unspecified obligations of reciprocity" (like gift exchange or mutual help), ${ }^{1}$ or as a multilateral understanding within a network of agents directly or indirectly connected with unspecified mutual obligations. The conditions in which the unspecified obligations of reciprocity become credible among the agents concerned are discussed later. For now it may be noted that there is a good body of psychological and experimental studies to indicate that reciprocity is deeply embedded in many social interactions (for example, Rabin 1998; Fehr and Gachter 2000; Benabou and Tirole 2006). Second, the utterance of speech or dispatch of other social symbols in social exchanges may well be generated by the sender's own direct interests or emotions (for example, appreciation, empathy, envy, jealousy, anger, and so on), but the messages are necessarily intended to have an impact on the object's emotional payoffs, either positively (for example, pride, satisfaction, consolation, retribution, and so on) or negatively (for example, shame, guilt, feeling of exclusion, and so on), the kinds of emotions that Elster (1998) characterizes as "social." In that sense, they are distinct from mere speech acts or the so-called cheap talk (transmission of information with no direct effect on the other's payoffs) in the signaling game in the economic domain. I assume that engaging in social exchanges may not necessarily be "cheap" for agents, because it may be costly in time and effort sacrificed, value of the gift, and so on.

Each agent can then derive positive or negative "social" payoffs (emotional payoffs) from the social actions of others that are directed toward him or her, as discussed and experimentally verified by neuroscientists. ${ }^{2}$ However, in order to expect continual positive actions from others, the agent must reciprocate positive 
actions toward them. If somebody is mean to the agent, he or she may wish to seek revenge from the opponent to stop further malicious actions and avoid "social pain." Thus the expected social payoff of an agent over time in the socialexchange domain will be conditional on the expected actions of others in response to the agent's own actions. Thus the agent's social payoff from the social exchange becomes in reduced form the function of his or her own actions, although implicitly via his or her own belief about the other's reactions to them. The unit of social payoff of his or her own actions may be measured by the marginal opportunity cost sacrificed in terms of the hedonic payoff associated with material consumption in the economic domain. ${ }^{3}$ The present value sum of the agent's expected social payoffs over time is referred to as his or her social capital. It represents the agent's expected capacity to derive positive net emotional payoffs over time as well as to derive benefits in other domains. Some scholars use the word "social capital" to refer to intangible collective assets that are held by society as a whole (for example, norms and the educational level of the society), analogous to tangible collective assets (for example, public goods and the commons). ${ }^{4}$ I conceptualize social capital as owned and used by individual agents (including individual corporations), however. ${ }^{5}$ As discussed shortly, social capital is distinguished conceptually from social norms and other social categories that evolve as societal outcomes of playing the social-exchange games.

An individual agent's social capital has two features. First, it is the object of individual investment. It depreciates without effort to sustain it. Thus agents exchange social symbolic actions in such a way that they consider the most fit or desirable in order to increase, as well as to make the best use of, their own social capital, albeit with bounded rationality. I provide concrete examples later, but at this point it is enough to point out that the basic structure of social exchanges indicates their strategic nature, albeit not in an exclusively self-regarding manner. Social exchanges based on reciprocity thus defined are different from altruism. Altruism is a form of unconditional kindness. It derives from the nature of agents' preferences and, as such, is not directly related to either strategic play or the endogenous rules of societal games.

Second, the individual agent's social capital depends not only on his or her own actions but also on his or her belief regarding the actions of others, the beliefs of others regarding the agent's beliefs, and so on. In this sense, the social-exchange game shares the same problem of infinite regress as the psychological games introduced by Geanakoplos, Pearce, and Stacchetti (1989) and applied by Rabin (1993). Recent achievement of epistemic game theory suggests that economic agents need a fair amount of common knowledge to arrive at equilibrium beliefs (Aumann and Brandenburger 1995). ${ }^{6}$ If agents are recursively engaged in social exchanges within an informative, homogeneous community, then their actions are more easily known and others' beliefs are more easily inferred. Namely, in the small community, experiences, information, and inferences are shared, resulting in the sharing of behavioral beliefs. Some standard of social exchanges, that is, norms of reciprocity, may then evolve through practices and customs. Such a standard of behavior, or "a behavioral 
strategy that is subscribed to by all" (Dasgupta 1999, 341), may be regarded as representing a Nash equilibrium of the psychological game.

The shared behavioral beliefs serve as a guide for the agents to act in a socially proper way. As a Nash equilibrium, it is not beneficial for agents not to follow them. It is believed that the failure to comply with the norm will be punished ("sanctioned" in the traditional sociological terminology) by the loss of social capital. Such loss may not necessarily be implemented by the extreme of external sanctions by others such as ostracism. If norms are internalized, they are followed even when others would not observe the violation, because not doing so may create guilt, shame, and other negative emotional payoffs. Such a moral sense need not be considered as derived from an abstract supernatural axiom or imposed primarily by an external authority, such as schools, churches, government, and so on. But it can be regarded as originating in practices. As Aristotle noted, "Moral goodness (etike) ... is the result of habit, from which it has actually got its name, being a slight modification of the word ethos" (Aristotle 1955, 91). Arrow also notes, "Internalized feelings of guilt and right are essentially unconscious equivalents of agreement that represent social decisions" (Arrow 1967, 79).

\section{Linking Economic- and Social-Exchange Games}

I have presented a simple argument that the genesis of norms may be regarded as endogenous outcomes in the social-exchange game. However, they do not necessarily have to be regarded as exogenous constraints on choice in the economic domain. Economic and social exchanges may be linked, and norms may evolve through interactions of the two. This is how the concept of individual social capital may still be relevant to an understanding of economic performance. As an example to exhibit the basic logic in a simple way, let me introduce a simple parable of the dilemma of the commons. That is, suppose that the commons are economically or aesthetically valuable to members of the community, but in order to keep them valuable in a sustainable manner, collective maintenance efforts are required. Efforts are costly to the members, so there are potential risks of free riding. Suppose that it is not technologically feasible to exclude any member from benefiting from the commons. For example, the remarkable growth of rice production in the early Edo period (from the seventeenth to the eighteenth centuries) in Japan was largely due to the continual reclamation of land and the associated development of irrigation systems in rural communities. However, rice paddies cultivated by the individual member families of the community were scattered and intermeshed due to the incremental land development by fairly homogeneous member families, while the irrigation system was such that water drawn from a canal was successively supplied from one paddy field to the next using the natural slope (the gravity system). ${ }^{7}$ In this case, the usual reputation mechanism to control a member's moral hazard behavior in the collective maintenance efforts may not have been feasible only on the commons-game domain. 
Suppose further that it is not feasible either politically or for some other reason to solve the problem by establishing individual property rights on scattered and intermeshed paddies or politically forcing the members to be engaged in the collective efforts against their individual incentives and wills. Suppose, however, that the members of the community are mutually engaged in various social exchanges (for example, mutual help as needed, participation in festivities, socializing during leisure and at work, and so forth), which allow the members to derive emotional (and practical) payoffs, with possible costs in time, effort, resources, psychological burden, and so on. The exclusion of any individual from the social exchanges implies the deprivation of his or her social capital.

Even though exclusion from the use of the commons is not technologically possible, shirking of collective efforts in developing and maintaining the commons may be punishable by excluding the shirker from the benefits of the social-exchange game, for example, ostracism. Indeed, in the case of Japan's Edo village referred to above, severe ostracism known as mura-hachibu was practiced against serious deviants (literally it implies an 80 percent exclusion from village collective actions except for funeral services and fire fighting). In any case, if the common beliefs prevail to the effect that shirking in the commons domain is punishable in the social-exchange domain, the cooperative participation of the members both in the commons game and the social-exchange game becomes the individual's best choice. Namely, given the shared beliefs, the cooperative states of play in both games are sustained. Such a standard of cooperative behavior, supported by the common beliefs, is referred to as a social norm.

In this example, the social-exchange game is "linked" to the commons game in such a way that the social capital of each agent created in the former game can be used as an incentive for cooperative behavior in the latter game. In that sense, it may be regarded as a game-theoretic restatement of the notion of "social embeddedness," which originated in the seminal writing of the economic sociologist Granovetter (1985). My point is that social norms are not imposed from outside economic domains that unilaterally embed and control economic behavior. Rather, the norm, or the "pattern of behavior" in Solow's terminology, is generated and sustained by agents' strategies to accumulate and use social capital to achieve their own higher overall payoffs inclusive of the social one. Later, I give some examples in which social networks and social capital endogenously evolve together with certain patterns of economic exchanges.

The linked-game approach may also clarify possibly varied roles of social norms for institutional transition. The endogenous view of social norms, which identifies social norms with an equilibrium outcome of reputation mechanisms in the economic domain itself, implies that norms emerge and disappear with relevant modes of economic transactions. Looking at this from a different angle, one may say that the inherent inertia of social norms is in general detrimental to the emergence of a new mode of economic transaction. Greif's historical comparative institutional analysis (Greif 1994, 2006) provides one instance in which this is true. The cultural belief among the Maghreb traders that dishonest trading will be 
punished by ostracism from their community was not shared by outsiders, so the Maghreb traders failed to expand their activities beyond the community. It is claimed that this was a major reason that they eventually lost competitiveness in long-distance trading in spite of their internal efficiency compared with the Genoese traders who relied on efficiency wage discipline to restrain the morally hazardous behavior of agents recruited from markets.

Did pre-market community norms need to be destroyed prior to market transition and replaced by entirely new market mores? How could the latter emerge? Traditional views, whether those of economists (such as Hicks 1969) or scholars in other social science disciplines, such as economic anthropology (Polanyi 1944; Geertz 1983), draw a sharp dividing line between the market economy and the pre-modern economy. A revisionist view contends, however, that under certain conditions, the rural community bound by cooperative norms could play a positive role in facilitating the gradual transition of pre-modern rural economies to market economies. This becomes possible when community norms can regulate morally hazardous behavior on both insiders and outsiders in the initial transition to mutual market relationships. The complete destruction of rural communities may be neither sufficient nor necessary for the emergence of external market relationships and their eventual integration into the market economy. However, as market relationships evolve, the value of social capital that individual members can accumulate through community relationships declines. Various historical and regional examples of the roles of community norms in the transition to the market economy are given in Aoki and Hayami (2001).

Social networks woven by individual investments in social capital also play a role in the development of new types of industrial organizations in which the creation of information is a vital source of competitiveness. In the evolution of the Silicon Valley clustering of start-up firms in the information technology industry, a fair amount of the sharing of information and cognition took place regarding the general direction of developmental potential (that is, the worldview and their position in it), while the development and design of particular modular elements of potentially innovative systems were firmly encapsulated within individual start-up firms. These two opposing aspects are actually complementary in producing innovation systems under high uncertainty. Tournament-like competition among start-up firms can be more conducive to innovation than research and development in an integrated firm under high uncertainty, because parallel development efforts by multiple firms provide option values (multiple experiments; Baldwin and Clark 2000), as well as extra incentives in the form of tournament-winning premiums (that is, the value of a marginal increase in the probability of winning a tournament due to extra efforts; Aoki and Takizawa 2002). However, in order for such a decentralized approach to be feasible, firms have to share information and vision regarding the future possibilities of the industry-that is, how their specialized modular products can be crucial elements in an evolving, innovative product system. Information sharing in this respect is mediated, or brokered, by venture capitalists, university professors, consultants, angels, and so on in a way reminiscent of academic exchanges (for example, Saxenian 1994; Podolny 2001; Burt 2005). To promote exchanges of useful information, reciprocity and mutual trust are needed to restrain exclusively self-regarding-take, 
do not give-kinds of attitudes, while informative brokers and helpful mentors are held in high esteem. Thus the dense social exchanges embedded the Silicon Valley mode of industrial architecture, and the agents who invested in social capital in this network, were able to expect economic and social returns in the form of future business opportunities and social status.

Recently some pessimism has prevailed among the venture capital community in Silicon Valley, however. Even after recovering from the bursting of the dot-com bubble in 2002, venture capital investment did not yield satisfactory rates of return, although an abundant amount of financial resources was invested in venture capital funds prior to the 2008 financial crisis. The rate of initial public offerings has declined dramatically since the crisis. It is not yet clear whether this is primarily the by-product of the financial crisis, the maturity of the information technology industry, which is transforming the industrial structure to a more integrated form, or something else. The older generation of venture capitalists who had operational and engineering knowledge has been retiring and been replaced by a new generation whose expertise is in finance more than in engineering and operations. If this is indeed so, the rate of social capital accumulated by the older generation of venture capitalists may be declining.

The organizational field of the commercialization of life sciences has been evolving somewhat differently, as Powell and others (2005) trace and depict with massive data sets and novel analytical methods. In the 1980s hundreds of small scientific firms were established based on scientific knowledge developed in university labs. Some of them soon matured into dedicated biotech firms. In the early days, however, they did not necessarily own skills in marketing drugs that they invented and often relied on pharmaceutical giants, which lacked a new base of knowledge in the rapidly advancing life sciences. This situation did not lead to the acquisition of dedicated biotech firms by the giants, as it did in the information technology field, but it did lead to complementary collaborations between them not only in marketing but also in development efforts. The collaborative networks evolved to include universities, public research organizations, and small start-up firms, as well as venture capital firms and the National Institutes of Health as funding agencies. Since no single organization had the full range of scientific, developmental, and managerial assets needed to produce new medicines, various types of organizations diversified their connections with others in research collaboration and financial support. Career mobility back and forth between universities and industries became commonplace. The overlapping, multiple bundling of organizations as horizontal networks has been evolving, with a small core of organizations at the center. The organizations in the centric positions are there because they have established reputations as being highly effective in having differentiated connections to diverse partners, not just by virtue of being commercially large. As suggested by the fact that these networks involve public research organizations such as universities and hospitals, investment in social capital, as distinct from market-specific reputation capital, has played a significant role for those organizations to be effective. Also, their relationships with other business organizations are not formally contractual; they are more informal and based on unspecified reciprocal obligations. They tend to reject aggressive business firms. 


\section{Social Capital and the Rat Race in the Organizational Context}

A norm matters even under a competitive framework of organizational architecture in which workers' jobs are standardized, mutually isolated, and paid for individually by piece-rate contracts, as Burawoy (1979) tells us in his fascinating field study at a Chicago factory. If the piece-rate system stands alone, it could generate a rat race among workers, triggering rate-cut ratchet effects. However, Burawoy depicts the workers as aiming at individually achieving_- "making out" in the workers' slang-a certain individual target rate. Some are satisfied with 125 percent, while others aim higher. But a ceiling (say, 140 percent) is imposed and well recognized by all members. If someone tries to achieve more than the ceiling, he is socially ostracized (although he might not mind being ostracized), while anyone who cannot attain 100 percent is scorned. The author argues that "making out" cannot be understood simply in terms of achieving greater individual earnings; its rewards include relieving boredom, obtaining social relations and psychological rewards, and restraining excessive competition. The culture of "making out" is generated by workers themselves, but once established, it is experienced as a set of externally imposed shop-floor norms. Those who do not follow, or cannot follow, lose or fail to achieve their social capital.

Under other circumstances, however, misaligned incentive contracts in the organization domain may create destabilizing competition among workers by inducing distorted incentives to invest in social capital to earn prestige. For example, in the process leading up to the 2008 financial crisis, the supposedly best and brightest competed on Wall Street and the City to achieve higher social status as symbolized by competence in designing high-yield derivative products. Financial engineering to hedge risks relies on mathematical tools, such as Ito's lemma, which can be applied to a calculus involving random Brownian movement of variables (say, securities prices). However, in the practical performance evaluation of financial engineers, the so-called tail risks (extreme events with small probability) are not properly taken into account. If events in the lower tail happen, the loss is borne largely by clients who are less informed, while the financial engineers receive higher rewards when events in the high tail occur. Thus they are induced to gamble. However, a large proportion of the increase in revenue from upper-tail events was not real gains; at least a portion of it should have been set aside as reserves for future risks (that is, considered as costs). Thus risk was endogenously amplified rather than hedged.

The "greed" of financiers is often blamed for its disastrous consequences. What does the greed mean in this case? The competition among financial engineers was not simply an economic desire to pursue the insatiable material payoff, but also a social one in which they strived to exhibit their superior competence and intelligence, resulting in emotional payoffs such as a sense of prestige or a feeling of being superior, awed, envied, and the like. Thus there was no ceiling in this rat race, even though a few extra million dollars might not have mattered much to them in a hedonic sense. The economic game and the social game were linked in such a way that the contractual rules of the economic game provided grounds for the culture of rat race in the social-exchange game, which in turn destabilized the state of play in the 
economic game. The primary fault may have lain in the misalignment of incentive contracts, but it was the mind-set of people absorbed in the culture that eventually led to the spectacular failure of major financial service firms.

\section{Do Share Markets Internalize Corporate Social Capital?}

Is there any point to regarding business corporations as engaged (and as ought to be engaged for unique societal benefits) in exchanges with the society of citizens at-large beyond their own markets and business partners? In posing a question in this way, I set aside matters such as corporate brands embodying accumulated reputations in their own markets (consumers' expectations regarding the quality of products, after-purchase services, timing of delivery, and the like). Costly signaling (such as advertisement) that would not directly affect the utility of the buyers is also left outside the scope of this discussion for a while (although advertisement may promote the so-called conspicuous consumption that enhances social payoffs). The distinction between market-specific reputation and social capital is sometimes subtle and ambiguous in practice, and it is often complementary, as seen later. I start by asking, Do business corporations accumulate (and ought they accumulate) social capital even outside their own product markets? And, if they do, what are the potential implications of this for their market and nonmarket behavior?

Indeed, corporations and citizens of society at-large may be viewed as directly and informally engaged in social exchanges. If a business corporation pollutes a natural environment or generates health hazards through its economic activities or products, it will be subjected to public reactions beyond its own market in the form of a bad social reputation, public protest, a boycott of its products, and so on, even if those economic activities or products are not illegal within the existing statutory framework. On the other hand, some corporations voluntarily provide resources for social benefits such as environmental protection, poverty reduction, public health, education and scientific research, and so on through their so-called corporate social responsibility (CSR) programs. They provide public goods or voluntarily reduce their external costs. As such, these contributions may not immediately contribute to their profits. In response to social contributions that are costly, however, citizens at-large may ascribe social recognition to corporations that provide these resources, contributing to the accumulation of their corporate social capital. To repeat, this corporate social capital is different from market-specific reputation capital. For example, a tobacco company may enjoy a good reputation among smokers, but its corporate social capital may be thin because its products cause health hazards (although tobacco companies are known to be big spenders on CSR programs to cope with their thin social capital accumulation). Why should business corporations be concerned with their social capital? As Friedman (1970) forcefully argues, is it not that individuals (individual shareholders in the capacity of citizens) should contribute to the provision of social benefits, not business corporations whose objective should be to maximize shareholders' value? 
Those who are committed to the so-called stakeholders-society view of corporate governance may argue that the accumulation of corporate social capital constitutes assets collectively beneficial to the stakeholders of the corporation: for example, the employees who have pride in working for an organization known to have a strong social reputation; environmentally conscious citizens who derive satisfaction from owning "green" stocks in the corporation even if they have to give up some dividend income; the embedding community that can expect sustained social contributions from the corporation; the social entrepreneur who has a "warm glow preference" (Baron 2007) for creating a CSR firm even at a financial cost; and so on. Indeed, in this way corporate social capital may cement corporate assets, both human and financial. I refer to the holders of these orientations as the CSR stakeholders.

Although the stakeholder-oriented view thus appears to have merit, a subtle aspect of corporate social capital may not be completely offensive even to the shareholder-oriented view of corporate governance. If investors try to select their portfolio only from stocks of business corporations engaged in CSR, the orthodox financial theory tells us that their financial performance must be worse because they restrict the universe from which stocks can be picked. However, empirical evidence suggests a possible correlation between expenditures for CSR and stock price performance (for example, Dowell, Hart, and Yeung 2000; King and Lennox 2001; Siegal and Vitaliano 2007; Heal 2005, 2009). ${ }^{8}$ Why? Two simple, but plausible, reasons could be that (1) profitable corporations may be more willing to contribute to costly CSR and that (2) CSR may be adopted to attract socially responsible consumers and thus enhance productivity (Baron 2007). The first possibility cannot be dismissed outright. For example, socially responsible investments, which now accounts for well over 10 percent of professionally managed funds in the United States, are not performing worse than other funds, although their portfolios are overweighted by the information technology-related stocks that showed relatively stronger growth from the mid-1990s to the financial crisis of 2008. However, event studies by Dasgupta, Laplante, and Maminge (2001) and Dasgupta and others (2004) find that capital markets react to recognition by the media or government of superior (inferior) environmental performance of corporations in a positively (negatively) correlated manner, suggesting causation from environmental performance to stock prices. Also, Siegal and Vitaliano (2007) find that when profits are treated as endogenous (that is, controlling profits due to the "strategic" CSR), they appear to have no influence on the decision to adopt CSR. So it is impossible to reject the possibility that capital markets internalize the values of corporate social capital to some extent.

The logic of capital pricing involving CSR due to Graff Zivin and Small (2005) and Baron (2007) suggests the following story. Suppose that a contribution of CSR is positively but partially (say, $\theta$ percent) reflected in the stock value of a corporation. This implies that for citizens-cum-investors who value the corporate giving more than that proportion, the stock price is virtually discounted. They can contribute to a social cause with less cost (that is, $100-\theta$ percent less). Therefore, contrary to Friedman's assertion, they are better off buying the stocks of the CSR firm than making a social contribution as individuals. Therefore, the 
presence of CSR corporations can increase aggregate social giving. Although the CSR entrepreneurs (and possibly other CSR stakeholders) bear the remaining cost (that is, $100-\theta$ percent of corporate giving), they can derive benefits not only by making their own contributions but also by expanding the opportunity sets for CSR shareholders by providing an alternative to personal giving. But the story is not yet finished.

Business corporations may also be engaged in the development and commercialization of environmentally friendly technology that not only may be appreciated by citizens as a whole but also potentially contribute to its profits: the CSR characterized as "strategic" by Baron (2007). The development can be costly, but its social value may not necessarily be fully appreciated by the potential buyers of its products alone. For example, the potential buyers of eco-friendly cars may be able to save expenditures for fuel after their purchase, but they may not be willing to bear the full development costs charged in the form of a higher price for the car. Thus the managerial calculus of market-specific reputation capital alone may not immediately convince a business corporation to pursue the costly technological development and its commercialization. However, as public concern with environmental degradation and sustainability of energy supplies rises, failure to do so may damage the accumulation of corporate social capital, while investment in environmentally friendly technology may contribute to its accumulation beyond immediate profits from car sales. The ascription of corporate social capital made possible by technological contributions to the cause of society would help the corporate organization to cohere and enhance its cognitive and financial abilities to continue to develop technology.

The attribution of corporate social capital may in turn amplify the value of market-specific reputation, because it may enhance the beliefs of potential buyers of products regarding their user cost-efficiency, durability, and the like, as well as the product's symbolic value to them (for example, environmental "conspicuous" consumption). In other words, corporate social capital may serve as a positive signal (analogous to advertisement) and improve the long-term profits net of the development cost. Market-specific reputation capital and corporate social capital can be mutually complementary. When de facto property rights in the global commons are shifting from the corporate sector to the public in general, individual corporations must cope with this substantive institutional change by improving their own technological potential and accumulation of social capital. In this situation, the CSR entrepreneur can be motivated to carry strategic CSR beyond the valuemaximizing level (Baron 2007).

Corporate CSR activities, pure and strategic combined, thus can link economic, commons, and social-exchange games between business corporations (and their stakeholders such as CSR entrepreneurs and employees) and concerned citizens. Concerned citizens may engage in those games by attributing corporate social capital to CSR corporations, investing in CSR stocks, as well as being potential buyers of the products of CSR corporations. Business corporations are engaged in these games as social givers as well as potential developers of profit-making, environmentally friendly technology. Corporations can do cognitively more than what the 
mere collections of individuals can do. This can be especially true with regard to the development of environmentally friendly and renewable energy technology, which requires innovative entrepreneurial initiative, organization of interdisciplinary inputs of knowledge and efforts, foresight, and patience, which CSR corporations, both small and large, may provide. Thus if the linkages of games as depicted in this paper can indeed evolve, strategies that have not been viable in economic calculations alone may become supportable as societal equilibrium.

\section{Concluding Remarks}

In this essay, I have made a conceptual distinction between social networks, norms, social status differentiation, and so on, on the one hand, and social capital, on the other. The former are social or institutional phenomena arising as outcomes of social-exchange games in which individual agents invest strategically in social capital. Social capital cannot be immediately measured in a way satisfactory to economists, because it cannot be priced in the domain of an economic game based on contractual agreement. But recent development of neuroscience suggests the future possibility of measuring social payoffs in terms of tradeoff relationships with hedonic payoffs. This possibility may suggest that a linked-game approach to social capital and its implications for economic performance are more promising. This approach might make feasible an analysis of socioeconomic network that is not possible using either an economic or a sociological approach. The former regards norms evolving endogenously only in the economic domain and the latter treats social categories as existing prior to individual economic choices. In effect, both treat social and economic factors in delinked manners. However, I have suggested a useful way to apply the linkedgame approach to the problem of the tragedy of the commons, which is becoming one of the most acute public issues of our time.

\section{Notes}

1. The notion of "unspecified obligations of reciprocity" was first emphasized by Blau (1964) as a distinctive characteristic of social exchanges.

2. For a brief survey, see Lieberman and Eisenberger (2008).

3. The tradability between monetary rewards and emotional payoffs is experimentally confirmed by some recent neuroscience studies founded on the notion of "common neuro-currency" (Montague and Berns 2002). A functional magnetic resonance imaging experiment by Izuma, Saito, and Sadato (2008) finds that the acquisition of one's good reputation activates rewards-related areas of the brain, notably the striatum, and these areas partially overlap the areas related to monetary rewards. See Fehr and Camerer (2007) for a similar study.

4. Putnam's social capital comes into being not through individual intentional action, but is said to be "inherited," with its origins hidden in the mists of the past (Putnam 1993). The existing stock cannot be individually owned. Hayami (2009) articulates a collectivist notion 
of social capital as "the structure of informal social relationships conducive to developing cooperation among economic actors with the effects of increasing social product."

5. An individualist view of social capital is elucidated and measured, and its implications are analyzed, by Glaeser, Laibson, and Sacerdote (2002).

6. Such common knowledge may be provided in the forms of culture as encapsulation of past experiences and some public indicators (cognitive societal categories) that make a certain equilibrium the focal point (Aoki 2010, ch. 4). Also see Arrow (1994) for the importance of social categories in achieving equilibrium.

7. The development of collective irrigation systems had quite different paths in Edo Japan and Yi Korea for historical, political, and geographic reasons. I discuss those differences and their possible implications for evolved social norms in some detail in the appendix to chapter 2 in Aoki (2001).

8. For a good survey of this and discussion of related subjects, see Heal (2005).

\section{References}

Aoki, Masahiko. 2001. Toward a Comparative Institutional Analysis. Cambridge, MA: MIT Press.

- 2010. Corporations in Evolving Diversity: Cognition, Governance, and Institutions. Oxford: Oxford University Press.

Aoki, Masahiko, and Yujiro Hayami, eds. 2001. Communities and Markets in Economic Development. Oxford: Oxford University Press.

Aoki, Masahiko, and Hirokazu Takizawa. 2002. "Information, Incentives, and Option Value: The Silicon-Valley Model.” Journal of Comparative Economics 30 (4): 759-86.

Aristotle. 1955. Ethics, trans. J. A. K. Thompson (rev. trans., H. Tredennick). London: Penguin Classics.

Arrow, Kenneth J. 1967. “The Place of Moral Obligation in Preference Systems.” In Human Values and Economic Policy, ed. Sidney Hook. New York: New York University Press.

- 1994. "Methodological Individualism and Social Knowledge." American Economic Review 84 (May): 1-9.

- 1999. "Observations on Social Capital.” In Social Capital: A Multifaceted Perspective, ed. Partha Dasgupta and Ismail Serageldin, 3-5. Washington, DC: World Bank.

Aumann, Robert J., and Adam Brandenburger. 1995. "Epistemic Conditions for Nash Equilibrium." Econometrica 63 (5): 1161-80.

Baldwin, Carliss Y., and Kim B. Clark. 2000. Design Rules: The Power of Modularity. Vol. 1. Cambridge, MA: MIT Press.

Baron, David P. 2007. "Corporate Social Responsibility and Social Entrepreneurship.” Journal of Economics and Management Strategy 16 (3): 683-713.

Benabou, Roland, and Jean Tirole. 2006. "Incentives and Prosocial Behavior." American Economic Review 96 (5): 1652-78.

Blau, Peter. 1964. Exchange and Power in Social Life. Brunswick, NJ: Transaction Publishers. Burawoy, Michael. 1979. Manufacturing Consent. Chicago: University of Chicago Press.

Burt, Ronald S. 2005. Brokerage and Closure: An Introduction to Social Capital. Oxford: Oxford University Press. 
Coleman, James. 1988. "Social Capital in the Creation of Human Capital.” American Journal of Sociology 94 (supplement): S95-120.

- 1990. Foundations of Social Theory, Cambridge, MA: Harvard University Press.

Dasgupta, Partha. 1999. "Economic Progress and the Idea of Social Capital.” In Social Capital: A Multifaceted Perspective, ed. Partha Dasgupta and Ismail Serageldin, 325-424. Washington, DC: World Bank.

Dasgupata, Partha, and Ismail Serageldin, eds. 1999. Social Capital: A Multifaceted Perspective. Washington, DC: World Bank.

Dasgupta, Susmita, Jong Ho Hong, Benoit Laplante, and Nlandu Maminge. 2004. "Disclosure of Environmental Violations and the Stock Market in the Republic of Korea." Policy Research Working Paper 3344, World Bank, Washington, DC.

Dasgupta, Susmita, Benoit Laplante, and Nlandu Maminge. 2001. "Pollution and Capital Markets in Developing Countries." Journal of Environmental Economics and Management 42 (3): 310-35.

Dowell, Glen, Stuart Hart, and Bernard Yeung. 2000. "Do Corporate Global Environmental Standards Create or Destroy Market Value?” Management Science 46 (8): 1059-74.

Elster, Jon. 1998. "Social Norms and Economic Theory." Journal of Economic Perspectives 3 (4): 39-117.

Fehr, Ernst, and Colin Camerer. 2007. "Social Neuroeconomics: The Neural Circuitry of Social Preferences." Trends in Cognitive Sciences 11 (10): 419-27.

Fehr, Ernst, and Simon Gachter. 2000. "Fairness and Retaliation: The Economics of Reciprocity." Journal of Economic Perspective 14 (3): 159-81.

Friedman, Milton. 1970. "The Social Responsibility of Business Is to Increase Its Profits." New York Times Magazine, September 13.

Geanakoplos, John, David Pearce, and Ennio Stacchetti. 1989. "Psychological Games and Sequential Rationality." Games and Economic Behavior 1 (1): 60-79.

Geertz, Clifford. 1983. Peddlers and Princes. Chicago: University of Chicago Press.

Glaeser, Edward, David Laibson, and Bruce Sacerdote. 2002. “An Economic Approach to Social Capital." Economic Journal 112 (483): 437-58.

Graff Zivin, Joshua, and Arthur Small. 2005. “A Modigliani-Miller Theory of Altruistic Corporate Social Responsibility." Topics in Economic Analysis and Policy 5 (1): art. 10.

Granovetter, Mark. 1985. "Economic Action and Social Structure: The Problem of Embeddedness." American Journal of Sociology 91 (3): 480-510.

Greif, Avner. 1994. "Cultural Beliefs and the Organization of Society: A Historical and Theoretical Reflection on Collectivist and Individualist Societies.” Journal of Political Economy 102 (5): 912-50.

- 2006. Institutions and the Path to the Modern Economy: Lessons from Medieval Trade. New York and Cambridge, U.K.: Cambridge University Press.

Hayami, Yujiro. 2009. "Social Capital, Human Capital, and Community Mechanism: Toward a Consensus among Economists." Journal of Development Studies 45 (1): 96-123.

Heal, Geoffrey. 2005. "Corporate Social Responsibility: An Economic and Financial Framework.” Geneva Papers 30 (3): 387-409.

- 2009. When Principles Pay: Corporate Social Responsibility and the Bottom Line. New York: Columbia University Press.

Hicks, John. 1969. A Theory of Economic History. Oxford: Oxford University Press. 
Izuma, Keise, Daisuke N. Saito, and Norihiro Sadato. 2008. "Processing of Social and Monetary Rewards in the Human Striatum." Neuron 58 (2): 284-94.

Kandori, Michihiro. 1992. "Social Norms and Community Enforcement." Review of Economic Studies 59 (1): 63-80.

King, Andrew A., and Michael J. Lennox. 2001. "Does It Really Pay to Be Green? An Empirical Study of Firm Environmental and Financial Performance." Journal of Industrial Ecology 5 (1): 105-16.

Knack, Stephen, and Philip Keefer. 1997. "Does Social Capital Have an Economic Payoff: A Cross-Country Investigation.” Quarterly Journal of Economics 112 (4): 1251-88.

La Porta, Rafael, Florencio Lopez-de-Silanes, Andrei Sheliefer, and Robert W. Vishny. 1997. "Trust in Large Organizations." American Economic Review 87 (2): 333-38.

Lieberman, Matthew D., and Naomi I. Eisenberger. 2008. "The Pains and Pleasures of Social Life: A Social Cognitive Neuroscience Approach.” Neuroleadership Journal 1: 38-43.

Montague, P. Reed, and Gregory S. Berns. 2002. "Neural Economics and the Biological Substrates of Valuation.” Neuron 36 (2): 265-84.

Ostrom, Elinor. 1990. Governing the Commons. New York: Cambridge University Press.

Podolny, Joel M. 2001. "Networks as the Pipes and Prisms of the Market." American Journal of Sociology 107 (1): 33-60.

Polanyi, Karl. 1944. The Great Transformation. New York: Farrar Rinehart.

Powell, Walter W., Douglas R. White, Kenneth W. Koput, and Jason Owen-Smith. 2005. "Network Dynamics and Field Evolution: The Growth of Interorganizational Collaboration in the Life Sciences." American Journal of Sociology 110 (4): 1132-205.

Putnam, Robert D. 1993. Making Democracy Work. Princeton, NJ: Princeton University Press.

Rabin, Matthew. 1993. "Incorporating Fairness into Game Theory and Economics.” American Economic Review 83 (5): 1281-302.

1998. "Psychology and Economics." Journal of Economic Literature 36 (1): 11-46.

Saxenian, Annalee. 1994. Regional Advantage: Culture and Competition in Silicon Valley and Route 128. Cambridge, MA: Harvard University Press.

Siegal, Donald S., and Donald F. Vitaliano. 2007. "An Empirical Analysis of the Strategic Use of Corporate Social Responsibility." Journal of Economics and Management Strategy 16 (3): 773-92.

Solow, Robert. 1999. "Notes on Social Capital and Economic Performance." In Social Capital: A Multifaceted Perspective, ed. Partha Dasgupta and Ismail Serageldin, 6-9. Washington, DC: World Bank. 